\title{
Endoscopic submucosal dissection of a neoplastic lesion in the epiglottis
}

The traditional methods of surgical treatment for supraglottic squamous cell carcinoma (SCC) include open supraglottic laryngectomy, transoral robotic surgery, and transoral laser surgery [1,2]. These surgical methods cause the patient not only great physical damage but also, as a consequence, a certain economic burden [3]. Exploring the possibilities of endoscopic resection for early lesions is therefore very worthwhile.

An early neoplastic lesion was found in the epiglottis of a 63-year-old man. His history showed that 2 years previously he had undergone extensive resection of SCC of the left hypopharynx and base of the tongue. Six months later he had undergone endoscopic submucosal dissection (ESD) of the right piriform fossa, and a further 6 months later (1 year before the current admission) esophageal ESD was performed. The neoplastic lesion in the epiglottis was found during the regular postoperative nasopharyngeal laryngoscopy.

The lesion was about $1.2 \mathrm{~cm} \times 0.7 \mathrm{~cm}$ in size and was assessed as a superficial raised lesion (0-Ila) with B1 and B2 type intraepithelial papillary capillary loops $(\mathrm{IPCL})$ ( $\triangleright$ Fig. 1, $\triangleright$ Fig.2). The biopsy histopathological finding was SCC. The boundary of the lesion was clear on narrow-band imaging and Lugol chromoendoscopy. Enhanced computed tomography $(\mathrm{CT})$ showed no evidence of metastasis.

ESD was performed to remove the lesion; no adverse events were observed

( Fig. 3, > Fig. 4; \Video 1). Pathology results revealed poorly differentiated SCC and showed that curative resection was achieved. On routine follow-up, gastroscopy and CT scan showed no recurrence or lymph node metastasis.

Despite the restricted space in the epiglottis, adopting ESD to treat SCC of the epiglottis has the advantages of (1) enabling curative resection with a clear margin in the whole surgical field and

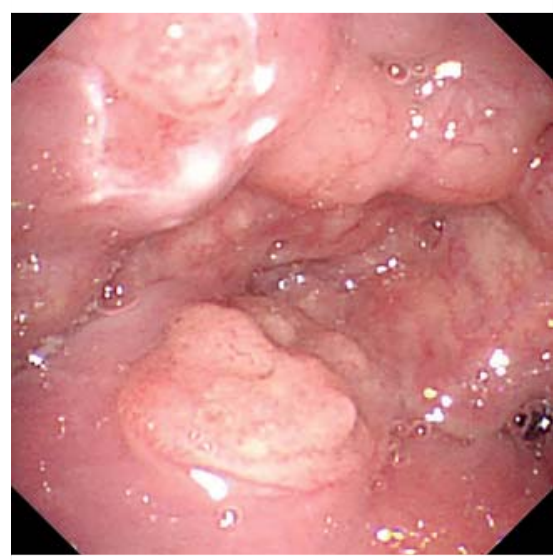

- Fig. 1 An early neoplastic lesion in the epiglottis of a 63-year-old man.

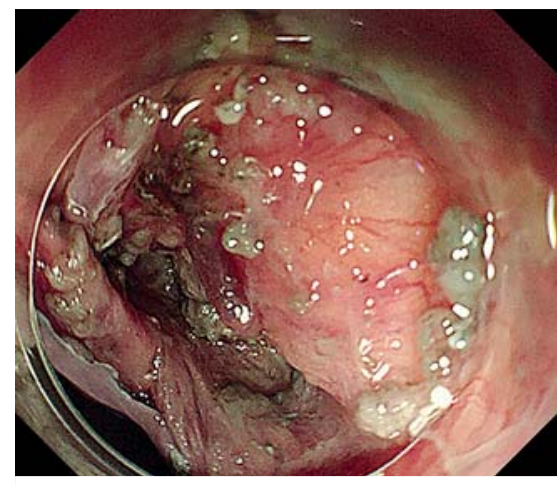

- Fig. 3 Artificial ulcer after endoscopic submucosal dissection.

(2) ease of operative technique via flexible endoscopy, which is minimally invasive and maintains organ integrity.

Endoscopy_UCTN_Code_TTT_1AO_2AG

Funding

the National Key Research and Development Program of China 2016YFC1302800

CAMS Innovation Fund for Medical Sciences (CIFMS) 2016-I2M-001

Sanming Project of Medicine in Shenzhen SZSM201911008

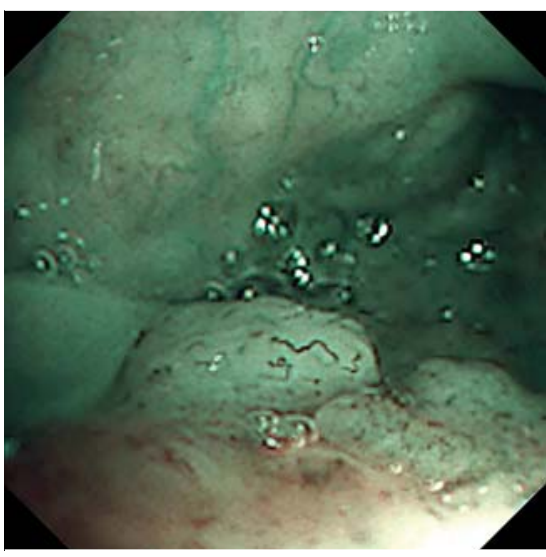

- Fig. 2 The early neoplastic lesion in the epiglottis under narrow-band imaging.

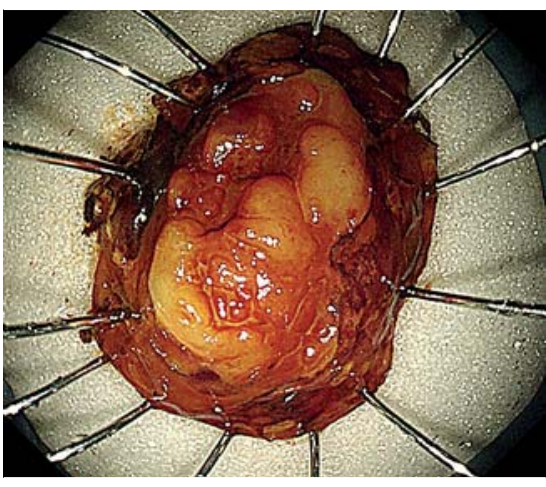

- Fig. 4 Surgical specimen of the lesion removed by means of endoscopic submucosal dissection.

the PUMC Youth Fund and the Fundamental Research Funds for the Central Universities 2017320012

the PUMC Graduate Innovation Fund 2019-1002-81

Beijing Science and Technology Program D17110002617004

Competing interests

The authors declare that they have no conflict of interest. 


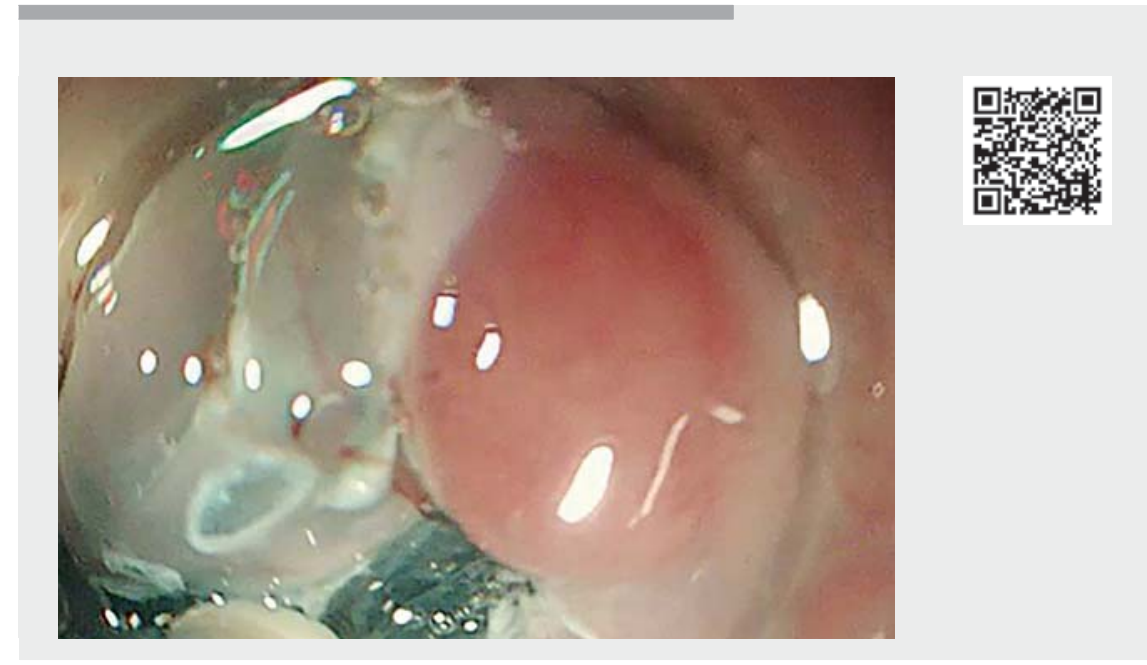

Video 1 Early neoplastic lesion in the epiglottis resected by endoscopic submucosal dissection.

The authors

\section{Zhengqi Li*, Yong Liu", Lizhou Dou, Yueming Zhang, Guiqi Wang}

Department of Endoscopy, National Cancer Center/National Clinical Research Center for Cancer/Cancer Hospital, Chinese Academy of Medical Sciences and Peking Union Medical College, Beijing, P. R. China

\section{Corresponding author}

\section{Guiqi Wang, MD}

Department of Endoscopy, National Cancer Center, 17 Panjiayuannanli, Beijing 100021 , P. R. China wangguiq@126.com

\section{Bibliography}

Endoscopy 2022; 54: E403-E404

DOI 10.1055/a-1559-1683

ISSN 0013-726X

published online 27.8.2021

(c) 2021. Thieme. All rights reserved.

Georg Thieme Verlag KG, Rüdigerstraße 14, 70469 Stuttgart, Germany

\section{ENDOSCOPY E-VIDEOS \\ https://eref.thieme.de/e-videos}

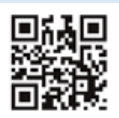

Endoscopy E-Videos is an open access online section, reporting on interesting cases and new techniques in gastroenterological endoscopy. All papers include a high quality video and all contributions are freely accessible online. Processing charges apply (currently EUR 375), discounts and wavers acc. to HINARI are available.

This section has its own submission website at

https://mc.manuscriptcentral.com/e-videos
[2] Karabulut B, Deveci I, Sürmeli M et al. Comparison of functional and oncological treatment outcomes after transoral robotic surgery and open surgery for supraglottic laryngeal cancer. J Laryngol Otol 2018; 132 : 832-836

[3] Patel TD, Echanique KA, Yip C et al. Supraglottic squamous cell carcinoma: a population-based study of 22,675 cases. Laryngoscope 2019; 129: 1822-1827

\footnotetext{
* Zhengqi Li and Yong Liu contributed equally
} to this article. 